\title{
The Second Digital Revolution
}

The new E/E architectures in vehicles and the function-oriented approach to software development are blurring the boundaries between the work of individual divisions and departments in car and commercial vehicle manufacturing companies, automotive industry suppliers and service providers. These changes are having an impact on traditional corporate structures that have grown up over time. 
Today

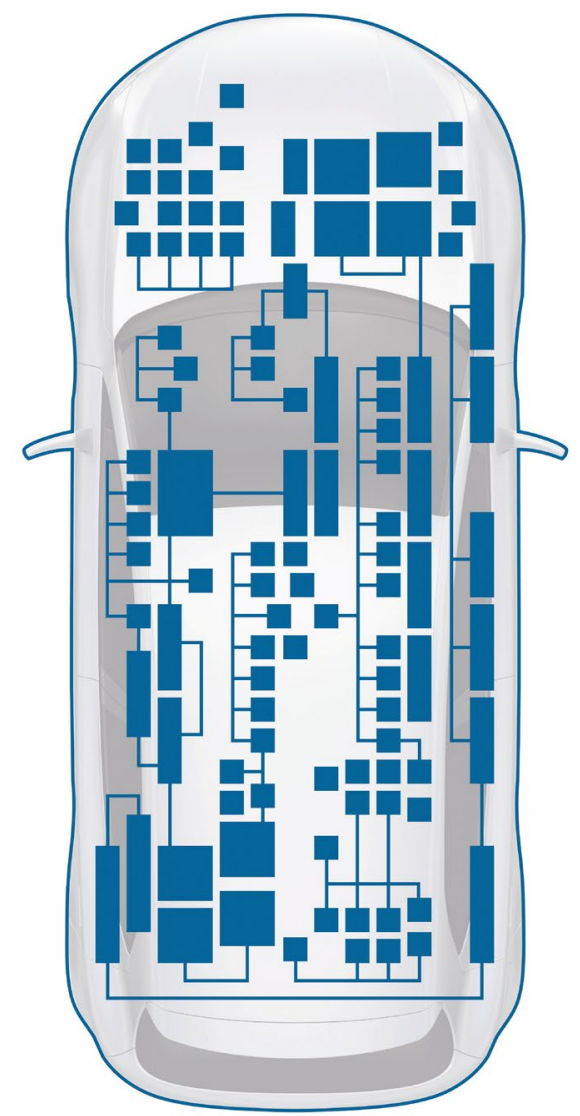

The E/E architecture with a central computer topology

\section{Tomorrow}

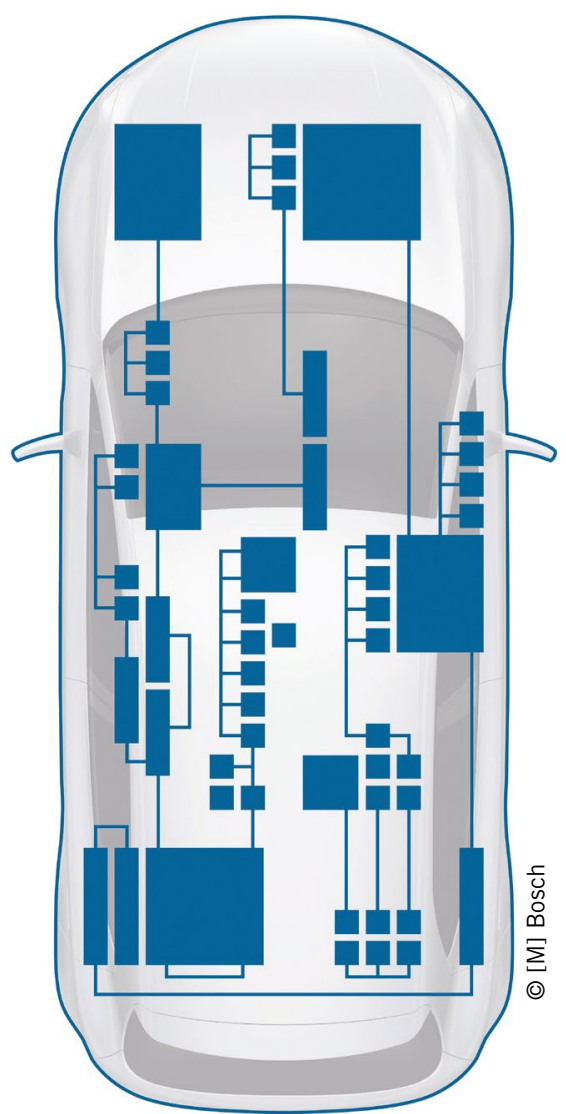

ware Lines of Code (SLOC) and 10,000 network signals. Conversations with our customers, however, have revealed the true numbers to be closer to 150 million SLOC and 20,000 network signals," explained Martin O’Brien, Senior Vice President Integrated Electrical Systems at Siemens, in ATZelectronics 3/2021 [1]. To put this into context, one million lines are equivalent to around 18,000 printed pages of text [2].

\section{PC-STYLE TOPOLOGIES}

This trend is growing because the increasingly complex functions that will be needed in the future for electric mobility, automated driving or integration into digital ecosystems can only be implemented using software. Experts estimate that software will soon represent $30 \%$ of the value of a car. At the moment, this figure is only $10 \%$. As a result, the volumes of data generated will reach almost unimaginable propor- tions. According to projections by the management consultancy Roland Berger, automated vehicles will need between 300 to 500 million lines of computer code [3]. At the same time, the extent of the networking in the $\mathrm{E} / \mathrm{E}$ architecture is continuing to grow because the new functions can only be implemented in interaction with all the subsystems, taking into account the effects on the overall vehicle level.

These software and hardware requirements are leading to a completely new approach to function development that represents the second digital revolution in the automotive world. At its technical heart are new topologies with a structure similar to that of the ubiquitous server architecture: In a networked E/E automotive architecture, a few high-performance computers are responsible for the increasingly extensive functions and take over the role of the individual, decentralized control units $[4,5]$. They form a basic universal hardware module that runs the function software, which is developed separately. The software programs are developed across the different domains in the overall vehicle network and are based solely around the function that they perform and control. As a result, the boundaries between the work of individual divisions and departments have become blurred and the whole process now involves teamwork on a large scale. The first carmaker to develop its electronic architecture for production models on the basis of this concept is Tesla. The current version of its architecture is known as Hardware 3. It is used in the Model 3, Model S and Model X and controls all the automated driving functions and the infotainment system from one component that consists of two computer cores stacked one on top of another. The first chip is a high-performance computer for the driving functions, which has been programmed using artificial intelligence methods, and the second is the infotainment controller.

\section{NEW BUSINESS UNIT AT BOSCH}

In order to prepare their organizations for these technical changes in the development process, many of the well-established car manufacturers and automotive industry suppliers have had to modify their corporate structures, with one example of these being Bosch. This industry leader has established a special new Cross-Domain Computing Solutions business unit, which will in future develop the basic software and middleware for car computers and control units and the software for vehicle functions such as parking and lane keeping assist systems and music streaming. In addition, Bosch is pooling the $\mathrm{E} / \mathrm{E}$ development expertise from other parts of its organization in the new unit. As a result, it will be possible to develop new functions much more quickly and pass them on to users in the form of software updates. Bosch promises that vehicle manufacturers will be able to offer their customers a consistent and impressive vehicle experience. Bosch is currently bringing together all its car multimedia activities and other parts of the Powertrain Solutions, Chassis Systems Control and Automotive Electronics business units under the umbrella of the new organization. "The new business unit 
will have around 17,000 employees working at more than 40 sites in over 20 countries," explained Matthias Klauda, Development Director of the new Bosch business unit.

\section{COUNTERACTING THE SILO MENTALITY}

Bosch regards the integration of the employees into the new business unit as an ongoing process with no end date. In order to avoid tension and friction, the company is putting the emphasis on transparent communications with its employees. "We are involving our people closely in the change process. We are explaining and discussing both our goals and the steps on the way to achieving them," said Michael Kram, who headed the integration project at Bosch, up until the launch of the new business unit in early 2021. "They are experts who have an in-depth understanding of the developments in the industry and respect the fact that this will put us in a leading position in the new digitalization movement."

The development service provider Porsche Engineering is counteracting the risk of a silo mentality developing by running an internal transformation program to make it easier for experts from traditional disciplines to make the move into software development. The goal is to gradually improve the company's internal processes and cooperation models so that it can respond quickly to specific new market requirements in individual areas. "We have a large number of engineers with 20 or more years of experience working for us who are prepared to move away from their current discipline and help to increase our software expertise. These employees will be particularly valuable to us after the transfer because they bring an understanding of both mechanics and electronics to the function development process," said Dirk Lappe, CTO of Porsche Engineering. The service provider offers its employees a development program that is tailored to their personal needs and supports them during the course of the program. "It is important to take an active approach to the transformation program and not to wait until we are forced to make a move by external events. This is why we are deliberately encouraging our employees to move into the new era, providing them with training on future trends at an early stage and promoting lifelong learning." Depending on each employee's new role and the skills they already have, the company works with them to define the specific stages and the content of their development process and to determine the length of the courses and other training measures. According to Porsche Engineering, it focuses in particular on ensuring the employees are not overstretched and on giving them the necessary support. "A successful move into a new world of work with new processes and products always requires a stable foundation. We must never forget that behind every transformation there are people," emphasized Lappe.

\section{VOLKSWAGEN BRINGS EXPERTISE BACK ON BOARD}

One car manufacturer that is currently expanding its electronics expertise on a grand scale is Volkswagen. It has set up a new company called Car.Software Organization where it is currently bringing together its electronic development functions. "We are exploiting to the full the Volkswagen Group’s potential for

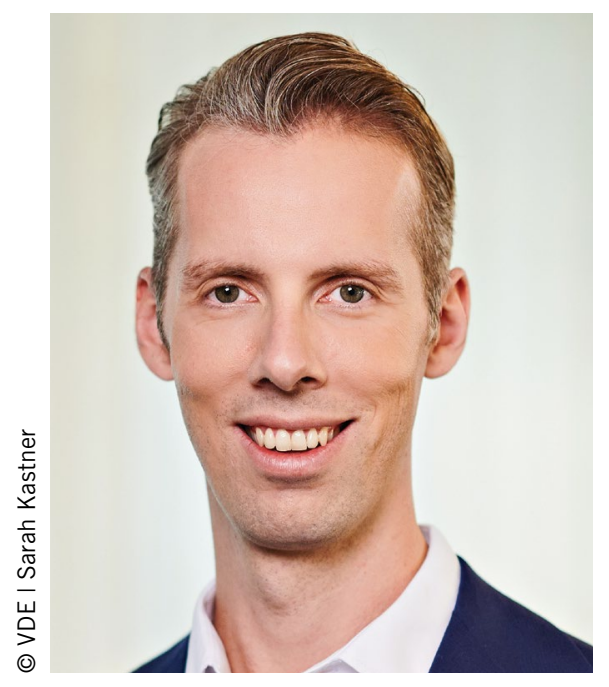

Dr. Ralf Petri

Head of the Mobility Business Unit at the VDE (German Association for Electrical, Electronic and Information Technologies)

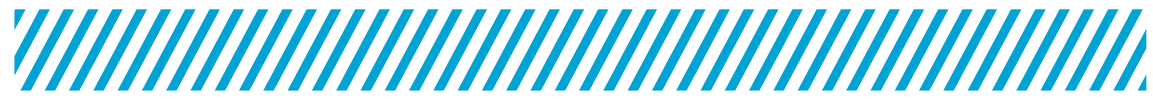 2 QUESTIONS FOR ...}

Everyone is talking about the current shortage of electronic components. What fundamental changes are needed to prevent this type of problem from happening in the future?

PETRI_ Past experience has showed that the automotive industry's supply chains are highly robust, despite their complexity. So it takes an earth-shattering event like the global coronavirus pandemic to have a negative impact on the supply chains, and one example of this was the shortage of electronic components. Nevertheless, challenges of this kind highlight areas for improvement where the European economic area can be further strengthened, for example by state subsidies, and where technical superiority can be achieved in Europe, in particular with regard to the core components of a vehicle.
A silo mentality slows down software development processes, in particular when cross-departmental issues arise. Could software development become the bottleneck for new vehicle functions in the automotive industry?

PETRI _ Over the years the focus of vehicle development has moved from pure hardware, such as the chassis, body and engine, to software. This trend has been reinforced with the shift toward electric mobility which involves only a small proportion of mechanical components. The car manufacturers have recognized the trend and are responding accordingly. For example, Volkswagen has brought all its software development together in the company Car.Software Organization in order to provide software for the entire group from under one roof. 


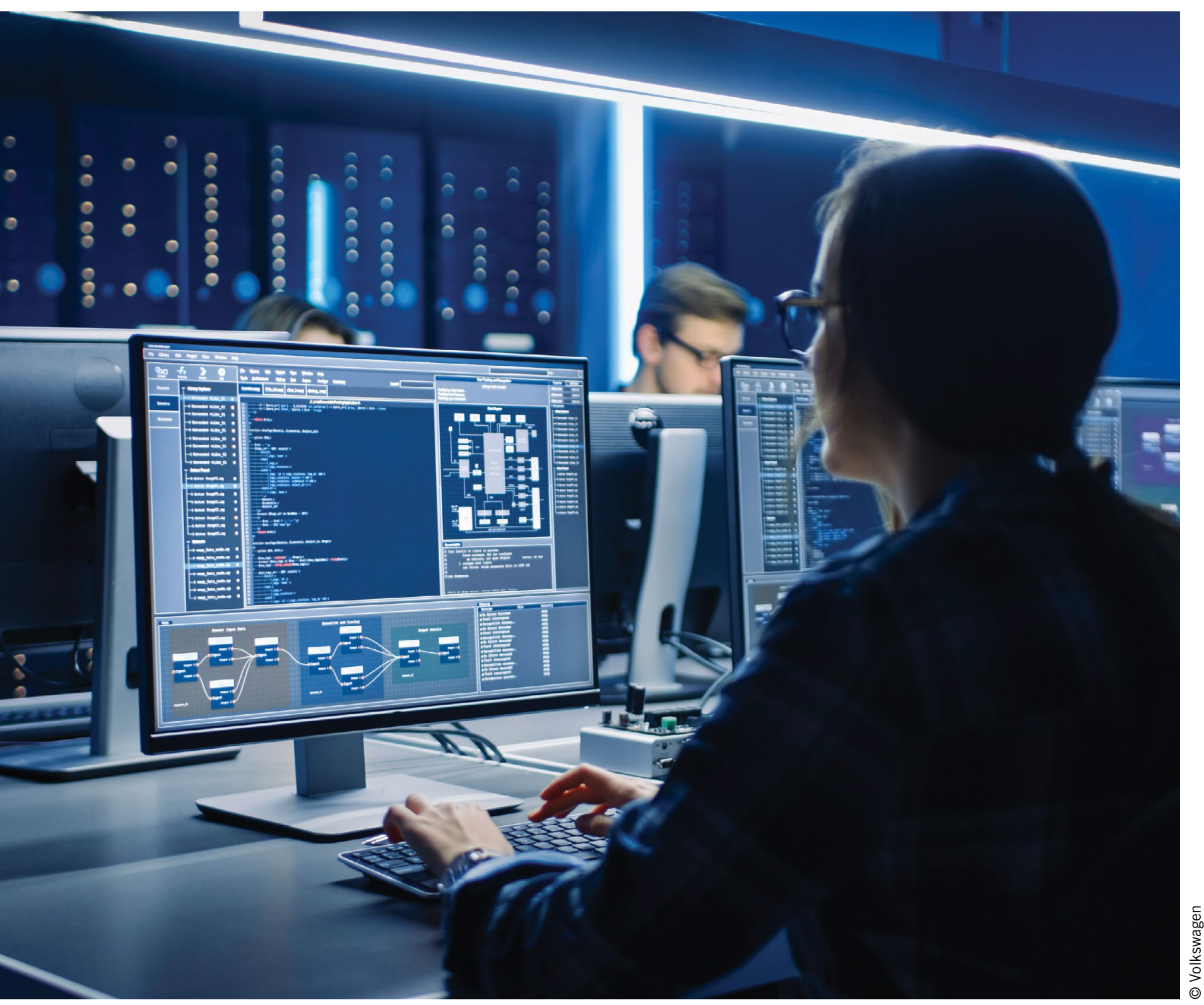

Volkswagen is bringing software development together in the Car.Software Organization

scaling up. It is important for us to put software closer to the heart of our development process and to see it as a central element and the starting point for what we do. This represents a paradigm shift and, at the same time, an important step forward for the Volkswagen Group on the road to becoming a software-driven mobility company," said Dr. Martin Hofmann, HR Director of Car.Software Organization. Alongside the creation of a software company for all the group's brands, this transformation also involves transferring the processes, the culture and the understanding of software as a product. "Any organization that wants to develop more software internally can't do this using mechanical engineering processes. That's why Car.Software Organization is entirely focused on agile software development," explained Hofmann.

In 2020, more than 2000 employees from Audi, Volkswagen and Porsche moved to the new company. In addition, around 500 specialists were hired and 1200 employees from associated companies joined the organization. Volkswagen plans to expand the company further over the next few years by bringing in employees from the group brands and by means of majority shareholdings and strategic partnerships. Car.Software Orga- nization has sites in Wolfsburg, Berlin, Ingolstadt and Stuttgart in Germany and also in the USA, China and India. "Car. Software Organization is in a strong position on both a national and an international level. It has a distinctive decentralized structure that is specific to software companies. Our operations are based where our talented employees are located and we are setting up highly effective competence hubs there. To ensure that the cross-site cooperation works well, the processes, methods and tools need to be coordinated with one another worldwide and to function regardless of where they are," said Hofmann. 
The first new electronic developments at Volkswagen include products such as the VW.OS vehicle operating system that has a connection to the data cloud and the new centralized E/E architecture known as E3. Parts of the concept, including its software update capability, have already been integrated into the new ID. electric vehicle platform. The complete package consisting of VW.OS, the group's own data cloud and the E3 architecture are likely to be ready for the next electric car developed by Audi and, from 2025 onward, will form part of all the group's new models.

In the future, much more software will be developed internally by the Volkswagen Group. "Our goal is to increase the in-house software in our cars from the current figure of $10 \%$ to $60 \%$ by 2025," explained Hofmann. In addition, according to Volkswagen this is primarily about building up knowledge and expertise and continuing to create innovations for customers, as well as expanding development and assessment skills. “Developing more software in-house doesn't mean doing everything ourselves. We will still work with external specialists and partners in the future. Ultimately, it is all about providing obvious added value and about ensuring that the products which our brands offer stand out in a positive way," said Hofmann.

Therefore, many suppliers and service providers are confident that their traditional business models with the car manufacturers will remain unchanged. "We see ourselves as a strategic partner for our customers and, on this basis, we assume that this dynamic will result in much closer cooperation over the next few years. Our goal is always to develop connected, intelligent cars for our customers," said Lappe. On behalf of Bosch, Klauda commented: "Understanding a system in depth and making the right decisions is one thing, but putting it all into practice yourself is something completely different. The new approaches are likely to lead to the creation of a new value chain, because software and hardware can now be developed and marketed separately." The strategy also involves a collaboration between Bosch and Microsoft that has recently been launched. This is all about developing a joint software platform to provide seamless connectivity for vehicles and the data cloud. The goal of the cooperation is to enable vehicle software to be developed more quickly and easily in the future, to be updated throughout the entire life of the vehicle and to be transmitted via the cloud to control units and car computers. The software platform will be based on the Microsoft Azure cloud computing platform and will include software modules created by Bosch.

Richard Backhaus
| OPINION

"Tesla has demonstrated what
the electronic architecture of the
future looks like, with a central
computer structure and software
that has been developed using
artificial intelligence and, most
importantly, can be updated over
the air. Of course, the situation
for a company like Tesla, which is
not tied to traditional structures,
is much simpler. This makes it all
the more important for the estab-
lished manufacturers and suppliers
to identify the opportunities of the
new electronic revolution at an early
stage and to make the most of them.
By 2030 , the market for software-
intensive electronic systems will
be growing by around $15 \%$ each year. This is a big enough cake to divide between all the market players that adapt to the new conditions. From my perspective, the innovation-driven German companies seem to be one step ahead of their international competitors."

\section{REFERENCES}

[1] O'Brien, M.: How to Bridge Boundaries in E/E Systems Development. In: ATZelectronics worldwide 3/2021, p. 62

[2] Desjardins, J.: How Many Millions of Lines of Code Does It Take? Online: https://www.visualcapitalist.com/millions-lines-of-code/, access: January 26, 2021

[3] Roland Berger (ed.): Global Automotive Supplier Study 2018. p. 49 [4] Küfen, J. et al.: Architectural Decisions as the Basis for Sustainable Mobility. In: ATZworldwide 4/2021, p. 50

[5] Cvijetic, N.; Tomazin, T.: Developing a Centralized Compute Architecture for Autonomous Vehicles. In: ATZelectronics 1-2/2021, p. 10-16

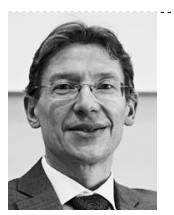

Richard Backhaus

is Correspondent of ATZ | MTZ | ATZelectronics. 